\title{
Simultaneous Determination of Cyclitols and Sugars Following a Comprehensive Investigation of 40 Plants
}

\author{
lleana Andreea Ratiu 1,2,3 Hossam Al-Suod $^{1,3} \cdot$ Magdalena Ligor $^{3} \cdot$ Tomasz Ligor $^{1,3} \cdot$ Aneta Krakowska $^{3}$. \\ Ryszard Górecki ${ }^{4}$ Bogusław Buszewski ${ }^{1,3}$
}

Received: 27 December 2018 / Accepted: 18 February 2019 / Published online: 5 March 2019

(C) The Author(s) 2019

\begin{abstract}
Due to the important features of widely unexplored cyclitols, a comprehensive qualitative and quantitative study is needed. Moreover, measuring the possible available amounts of identified components in plant material represents a stringent need, due to their importance in phytomedicine and their use in food. The purpose of this study was to realize an extended investigation mainly of cyclitols, but of sugars and sugar alcohols as well, from natural sources. Thus, 17 target compounds ( 7 cyclitols and 2 sugar alcohols and 8 sugars) extracted from medicinal and edible plants are reported. All detected components were simultaneous separated in just one chromatographic run, using a single GC column. A number of 52 sources coming from 40 species were studied. Thus, we report 37 new sources of cyclitols. Moreover, almost for all cyclitols, the richest source was not investigated previously. Therefore, the obtained results can represent a valuable material for food, pharmaceutical, medical, or cosmetic industry interested in the use of cyclitols.
\end{abstract}

Keywords Cyclitols $\cdot$ Sugars and sugars alcohols $\cdot$ Relevant natural sources

\section{Introduction}

Carbohydrates represent a complex class of organic compounds naturally occurring in plant material. The main sources of energy for normal human body functions, especially brain functions, are actually the carbohydrates (Muir et al. 2009). Cyclic polyols (cyclitols) are secondary metabolites that are produced in plant and have an essential contribution

Ileana Andreea Ratiu and Hossam Al-Suod equal contribution between authors

Bogusław Buszewski

bbusz@chem.umk.pl

1 Interdisciplinary Centre of Modern Technologies, Nicolaus Copernicus University, Wileńska 4, 87-100 Toruń, Poland

2 Faculty of Chemistry and Chemical Engineering, Babeș-Bolyai University, 11 Arany Janos, RO-400028 Cluj-Napoca, Romania

3 Department of Environmental Chemistry and Bioanalytics, Faculty of Chemistry, Nicolaus Copernicus University, Gagarina 7, 87-100 Toruń, Poland

4 Department of Plant Physiology and Biotechnology, Faculty of Biology and Biotechnology, University of Warmia and Mazury, Oczapowskiego 1A, PL-10-719 Olsztyn, Poland in plant self-defense against hostile environmental conditions like water and salt stress. Their biological activity as anti-diabetic, anti-inflammatory, or anti-cancer agents was already described by several groups of researchers (Rengarajan et al. 2015; Singh et al. 2001; Sivakumar and Subramanian 2009). Cyclitols also secure the good cell functioning, being responsible for signal transduction, biogenesis and cell wall formation, phosphate storage, and osmoregulation (Egamberdieva et al. 2012). Many other important pharmaceutical properties of cyclitols were described. For example, myo-inositol was reported as efficacious in treating panic attacks, premenstrual dysphoria, or depression obsessive-compulsive disorders (Carlomagno et al. 2011). Protective effect of D-pinitol, utilized in the treatment of hypertension, rheumatoid arthritis, and cardiovascular and neurological disorders, was described as well (Zheng et al. 2017). Moreover, D-chiro-inositol and myo-inositol are demonstrated to be efficacious in improving ovary functionality by increasing the ovulation rate in women affected by polycystic ovary syndrome (Monastra et al. 2017).

Sugars are synthesized in plants and in the body, they are absorbed immediately or stored in the form of glycogen (Murphy and Johnson 2003). Frequently, foods are supplemented with sugars during preparation process, to enhance sensorial quality, to preserve the edibles for longer time or to 
favor the fermentation substrate. Nevertheless, sugar overconsumption became a big concern (Millar et al. 2014). Many studies reported diabetic problems, dental diseases, attentiondeficit combined with hyperactivity disorders (ADHD), and obesity entailed by huge intake of sugars ingested by children from chocolates, candies, and even from basic everyday foods (Feig 2010; Gross et al. 2004; Kim and Chang 2011; Peres et al. 2016). Conversely, the use of sugars alcohols (sorbitol or mannitol) as sweeteners became an alternative to reduce the uses of classical sugars (Grabitske and Slavín 2008). In contrast to classical sugars, which were intensively restricted, the acceptable daily intake (ADI) for sugar alcohols has been fixed by the Joint FAO/WHO Expert Committee on Food Additives (JECFA) as "Not specified." Sugar alcohols are accepted as well in UE, Japan, and USA (Japan Ministry of Health, Labour and Welfare (2007); Regulation (EC) no. 1333/2008 of the European Parliament and of the Council on food additives, 2018; United States Food and Drug Administration: 21CFR 2018). However, sugar alcohols' excess can lead to stomach disturbances (Ruskone-Fourmestraux et al. 2003).

Currently, several analytical methods are available for quantification of sugars and cyclitols (Al-Suod et al. 2017, 2018a, Al-Suod et al. 2019). High-performance liquid chromatography (HPLC) with different detectors was used for the analysis of this type of compounds (Filip et al. 2016; Márquez-Sillero et al. 2013; Shanmugavelan et al. 2013). Therefore, HPLC allows for rapid and simultaneous analysis and due to the large number of publications, it seems that it has been reported to be the most utilized analysis technique for this specific application. Capillary electrophoresis (CE) has the ability for fast analysis of sugars like fructose, glucose, and sucrose (Dominguez et al. 2016), but there is no application for assorted sugars, sugar alcohols, or cyclitols. Another simple option suitable for determination of sugar class is high-performance anion exchange chromatography with pulsed amperometric detection (HPAEC-PAD). As in case of HPLC and CE, a derivatization step is not required, but experimental results proved that the technique is providing poor resolution for some components like sucrose (Pico et al. 2015). Three different cyclitols extracted from alfalfa plant were identified using matrix-assisted laser desorption/ionization with time-offlight mass spectrometry (MALDI-TOF-MS); however, the technique is useful and sensitive for identification, but not suitable for quantification (Al-Suod et al. 2018b).

Liquid chromatography-mass spectrometry (LC-MS) proved to be suitable in analyzing sugars, sugar alcohols, and cyclitols (Dewangan et al. 2014; Ghfar et al. 2015). LCMS can detect low concentrations, below ppm level. However, the required instrumentation is not cheap, matrix effects can appear, and a laborious sample pretreatment is necessary. Gas chromatography coupled with mass spectrometry (GC-MS) is one of the most sensitive and powerful tool suitable for the analysis of this type of components. GC-MS affords high sensitivity and resolution at below ppm levels for both sugars and cyclitols. In contrast with LC-MS, for GCMS, a derivatization step is required. This fact may have the inconvenient to be time consuming and to involve reagent usage, and also to the apparition of some potential unwanted contamination and/or composition modification of the sample. Nevertheless, the advantages of derivatization consist in both volatilization of target components by binding them to silyl groups and also in serving as a purification step, once other non-volatile existing components are not going to be included into the analysis. Moreover, the silyl groups' intercalation can lead to a more favorable ion fragmentation pattern used for structure investigations (Ligor et al. 2018). A major advantage of GC-MS compared to LC-MS is the high reproducibility of generated mass spectra using EI (electron impact). The EI ionization process used in GC-MS is a hard ionization that produces very reproducible mass spectra from one instrument to another (Ligor et al. 2018).

Sugars, sugar alcohols, and cyclitols are found in plant material. The knowledge of the relevant sources is a crucial step that allows for the plant selection for a convenient industrial exploitation (Al-Suod et al. 2018a; Ratiu et al. 2018). Sugar alcohols are typically produced by conversion of fructose and glucose using bacteria and yeasts (Ghoreishi and Shahrestani 2009). Their isolation from natural sources was reported as well. For example, in China, mannitol isolation from seaweed is very common (Deis and Kearsley 2012). In contrast with sugars and sugar alcohols, relevant sources of cyclitols still remained uninvestigated. The strength of our study consists in reporting 52 important sources of cyclitols, which include 40 species of plants, most of them part of everyday diet. Because our target compounds are present in different amounts in the various morphological parts of plant, different parts (leaves, stems, flowers, roots, seeds or pods) were analyzed. A total number of 7 cyclitols, 2 sugar alcohols, and 8 sugars were identified and quantified. An important achievement worth to be highlighted is that all the mentioned components were analyzed at the same time, on the same GC column. To the best of our knowledge, 37 from 52 investigated sources were not reported so far.

\section{Material and Methods}

\section{Plant Material and Chemicals Involved}

Most of these plants were purchased from the special herbal stores or grocery stores. Some of them were cultivated in Poland. The full list including plant species analyzed, purchasing manufacturer, and origin country is presented in Table 1.

Chemicals D-pinitol, myo-inositol, scyllo-inositol, Dchiro-inositol, ononitol, bornesitol, allo-inositol, D-glucose, 
Table 1 The source and origin of plant species investigated

\begin{tabular}{|c|c|c|c|}
\hline No & Plant species & Origin country & Manufacturer \\
\hline $\begin{array}{l}1 \\
2\end{array}$ & $\begin{array}{l}\text { Allium ursinum } \\
\text { Sorbus aucuparia }\end{array}$ & Poland & Dary Natury \\
\hline 3 & Trigonella foenum-graecum & & \\
\hline 4 & Carum carvi & India & \\
\hline 5 & Myristica fragrans & & \\
\hline 6 & Laurus nobilis & Turkey & \\
\hline 7 & Elettaria cardamomum & Guatemala & \\
\hline 8 & Eugenia caryophyllus & Brazil & \\
\hline $\begin{array}{l}9 \\
10\end{array}$ & $\begin{array}{l}\text { Taraxacum officinale } \\
\text { Solidago virgaurea }\end{array}$ & Poland & Kawon-Hurt \\
\hline 11 & Sambucus nigra & & \\
\hline 12 & Rosa canina & & \\
\hline $\begin{array}{l}13 \\
14\end{array}$ & $\begin{array}{l}\text { Chamomilla recutita } \\
\text { Salvia officinalis }\end{array}$ & Poland & Herbapol \\
\hline 15 & Vaccinium myrtillus & & \\
\hline $\begin{array}{l}16 \\
17\end{array}$ & $\begin{array}{l}\text { Calendulae anthodium } \\
\text { Mentha piperita }\end{array}$ & Poland & Flos \\
\hline 18 & Hypericum perforatum & & \\
\hline $\begin{array}{l}19 \\
20\end{array}$ & $\begin{array}{l}\text { Solanum tuberosum } \\
\text { Anethum graveolens }\end{array}$ & Poland & Grocery stores \\
\hline 21 & Beta vulgaris & & \\
\hline 22 & Petroselinum crispum & & \\
\hline 23 & Allium sativum & & \\
\hline 24 & Daucus carota subsp. sativus & & \\
\hline 25 & Lactuca sativa & & \\
\hline 26 & Agaricus bisporus & & \\
\hline $\begin{array}{l}27 \\
28\end{array}$ & $\begin{array}{l}\text { Curcuma longa } \\
\text { Zingiber officinale }\end{array}$ & India & \\
\hline 29 & Oryza sativa & Jordan & \\
\hline $\begin{array}{l}30 \\
31\end{array}$ & $\begin{array}{l}\text { Capsicum annuиm } \\
\text { Brassica oleracea var. acephala }\end{array}$ & Holland & \\
\hline 32 & Brassica oleracea & & \\
\hline 33 & Allium сера & Austria & \\
\hline 34 & Ceratonia siliqua $L$. & Spain & \\
\hline $\begin{array}{l}35 \\
36\end{array}$ & $\begin{array}{l}\text { Ipomoea batatas } \\
\text { Arachis hypogaea }\end{array}$ & China & \\
\hline $\begin{array}{l}37 \\
38\end{array}$ & $\begin{array}{l}\text { Phacelia tanacetifolia, } \\
\text { Medicago sativa L., }\end{array}$ & Poland $^{\mathrm{a}}$ & $\begin{array}{l}\text { Cultivated without the use of any treatments } \\
\text { and collected in August } 2017\end{array}$ \\
\hline 39 & Camelina sativa $L$. & & \\
\hline 40 & Lupinus perennis & & \\
\hline
\end{tabular}

${ }^{\text {a }}$ Bobrowniki, Kuyavian-Pomeranian Voivodeship
D-fructose, D-mannose, D-mannitol, lactose, D-sorbitol, and D-(+)-turanose with purity $\geq 95 \%$ (used as standards) and trimethylsilylimidazole TMSI (used for derivatization) were all purchased from Sigma-Aldrich (St. Louis, MO, USA). Sucrose, xylose, galactose, (purity $\geq 98 \%$ ), 96\% ethanol, $70 \%$ ethanol, and pyridine were purchased from Avantor (Gliwice, Poland). Methanol (HPLC grade, $\geq 99.9$ ) was obtained from Sigma-Aldrich (Steinheim, Germany). Ultra-pure water was obtained from a Milli-Q water system (Millipore,
Bedford, MS, USA). The columns used for SPE were CHROMABOND ${ }^{\circledR} \mathrm{C} 18$ ec columns, purchased from Macherey-Nagel (Düren, Germany).

\section{Sample Preparation}

Accelerated solvent extraction (ASE) was carried out using a Dionex ASE 350 system (Thermo Scientific, Waltham, MA, USA) equipped with an auto-sampler carousel and a 
collection tray that allowed for sequential extraction of up to 24 samples. Some plant material was purchased dried, while others required being dry in the laboratory. The drying was performed in the oven, at $30{ }^{\circ} \mathrm{C}$, during 24 to $48 \mathrm{~h}$, depending by plant material. The plant material was grinded using a laboratory mill, until a fine powder was obtained. The resulted powder was passed through a sieve with mesh size $1 \mathrm{~mm}$. Consequently, particles with the dimension equal of less than $1 \mathrm{~mm}$ were used (Krakowska et al. 2018). For each plant included in the study, $1 \mathrm{~g}$ of grounded powder was placed in a $10 \mathrm{~mL}$ stainless steel extraction cell and extracted using water as a solvent. The extraction was performed at $50{ }^{\circ} \mathrm{C}$, $10 \mathrm{MPa}$, for three cycles (18 min each), according to the methodology developed by Ruiz-Aceituno et al., which, as a result of a PLE optimization found this parameters to be the most suitable for inositol's extraction. SPE cartridges were used for both purification and pre-concentration step (RuizAceituno et al. 2014). CHROMABOND® C18 ec columns were employed to remove non-polar components. The solution obtained after extraction process was filtered through $\mathrm{CA}$ membrane $(0.22 \mu \mathrm{m} \times 25 \mathrm{~mm})$ and after that passed through a column of CHROMABOND® $\mathrm{C} 18 \mathrm{ec}$, previously activated with $3 \mathrm{~mL}$ of methanol and equilibrated with $3 \mathrm{~mL}$ of water. In the next step, the water from purified solution was evaporated to dryness under a nitrogen gas flow, using a heating block thermostated at $40{ }^{\circ} \mathrm{C}$. Finally, the dried sample was redissolved in $5 \mathrm{~mL}$ of pyridine. From this stock, $150 \mu \mathrm{L}$ of pyridine solution was derivatized using $150 \mu \mathrm{L}$ of TMSI at $80^{\circ} \mathrm{C}$ for $150 \mathrm{~min}$, and $1 \mu \mathrm{L}$ of each sample was injected into the GC injection port. For quantification, derivatized standards with known concentration were injected. All the samples were analyzed in triplicate. The concentration ranges for each standard are mentioned in Table 2.

\section{Gas-Chromatographic Analysis}

GC-MS analyses were performed to identify and quantify sugars and cyclitols extracted from 40 species of plants. The analysis was carried out using an AutoSystem XL gas chromatograph coupled with mass spectrometer TurboMass (both from Perkin Elmer, Norwalk, CT, USA) using He at $1 \mathrm{~mL} / \mathrm{min}$ as carrier gas. An RTX-5MS capillary column $(30 \mathrm{~m} \times$ $0.25 \mathrm{~mm}, 0.250 \mu \mathrm{m}$ ) (Restek, Bellefonte, PA, USA) was used. The oven temperature was programmed as follows: initial temperature of $90^{\circ} \mathrm{C}$ was kept for $1 \mathrm{~min}$, and then temperature was increased, at a rate of $10.0^{\circ} \mathrm{C} / \mathrm{min}$, to $300{ }^{\circ} \mathrm{C}$ and maintained for $5 \mathrm{~min}$ at this temperature. Injector temperature was $260{ }^{\circ} \mathrm{C}$, and injections were made in the split mode with a split flow 1:25. Mass spectrometer was operating as follows: ion source temperature $280^{\circ} \mathrm{C}$, ionization energy $70 \mathrm{eV}$ (electron impact ionization), $\mathrm{m} / \mathrm{z}$ scanning range 35-650 Da. The acquisition of chromatographic data was performed by means of
TurboMass (Perkin Elmer) and mass spectrum library NIST 2005 (Gaithersburg, USA).

\section{Validation Parameters}

All calibration data: average of the peak retention time $\left(R_{t}\right)$, calibration equations using peaks area for GC-MS detection, linearity presented as a correlation coefficient $\left(\mathrm{R}^{2}\right)$ of the calibration curves, and limits of detection (LOD) and quantification (LOQ), precision (RSD) as a relative standard deviation estimated for peak areas are presented in Table 2.

The limit of detection (LOD $=3 \times \mathrm{SDxy} / \mathrm{b}$, where SDxy is the standard deviation and $b$ is the slope) and the limit of quantification $(\mathrm{LOQ}=10 \times \mathrm{SDxy} / \mathrm{b})$ were calculated with acceptable precision and accuracy. LOD ranged from 0.10 to $44.91 \mathrm{ng}^{*} \mathrm{~mL}^{-1}$ and LOQ from 0.31 to $136.08 \mathrm{ng}^{*} \mathrm{~mL}^{-1}$. Using our method, we obtained LODs lower than other authors for some components and higher for others (GomezGonzalez et al. 2010; Mechri et al. 2015). The accuracy was evaluated as a recovery at each concentration over 80-120\% of the analyte range concentrations. The results showed that average recovery at different level of concentration ranged from 94.9 to $98.3 \%$, and RSD was $2 \%$. The calibration curve parameters have a very good linearity, with a correlation coefficient R2 ranging between 0.9990 and 0.9997 . The amount of each identified target was calculated using calibration curves created based on concentrations of standards presented in Table 2. Three repetitions were realized for each concentration, and the same protocol was followed for extract samples. Retention indexes were calculated using Kovats retention index equation and were established based on mixed alkane standards from $\mathrm{C} 9$ to $\mathrm{C} 27$.

Selected ion mode was used to calculate the concentrations of fructose and mannose, peaks which did not highlight clear separation from the base line in extract samples. We utilized the ion with $\mathrm{m} / \mathrm{z} 437$ to calculate the fructose amount and the ion with $\mathrm{m} / \mathrm{z} 305$ for mannose quantification.

\section{Statistical Approaches}

Statistical approaches: bar graphs of components were created using IBM SPSS Statistics, version 21; sunburst chart was created in Microsoft Excel 2016, and Microsoft Power Point 2010 was used to prepare the chromatogram figure.

\section{Results and Discussion}

\section{General Remarks}

All detected components were simultaneously separated in just one chromatographic run, using a single GC column. It was noticed that some components (like fructose and glucose) 
Table 2 Parameters of calibration curves and concentration ranges of quantified compounds

\begin{tabular}{|c|c|c|c|c|c|c|c|c|c|}
\hline Identified targets & RI & $\mathrm{R}_{\mathrm{t}}(\min )$ & $m / z$ & $\begin{array}{l}\text { Calibration } \\
\text { Equation }\end{array}$ & $\mathrm{R}^{2}$ & $\begin{array}{l}\mathrm{RSD} \\
(\%)\end{array}$ & LOD ng/mL & $\begin{array}{l}\text { LOQ } \\
\mathrm{ng} / \mathrm{mL}\end{array}$ & $\begin{array}{l}\text { Concentration } \\
\text { ranges }(\mu \mathrm{g} / \mathrm{mL})\end{array}$ \\
\hline \multirow[t]{2}{*}{ Xylose } & 1728 & 11.50 & $73,204,191,217,147$ & $y=6 \mathrm{E}+08 x+77,534$ & 0.9994 & 0.32 & 3.34 & 10.12 & $0.25-10.00$ \\
\hline & 1735 & 11.57 & $73,204,191,217,147$ & $y=3 \mathrm{E}+08 x-13,007$ & 0.9993 & 0.33 & 3.28 & 9.94 & $0.25-10.00$ \\
\hline D-mannose & 1832 & 12.60 & $\begin{array}{l}73,305^{\mathrm{a}}, 147,306,103, \\
\quad 204,217\end{array}$ & $y=3 \mathrm{E}+07 x+11,656$ & 0.9993 & 3.08 & 20.74 & 62.85 & $0.50-1000.00$ \\
\hline \multirow[t]{3}{*}{ D-fructose } & 1840 & 12.68 & $\begin{array}{l}73,217,147,68,437^{\mathrm{a}} \\
\quad 75,204\end{array}$ & $y=6 \mathrm{E}+06 x-5366$ & 0.9990 & 2.11 & 1.07 & 3.26 & $0.50-700.00$ \\
\hline & 1847 & 12.75 & $\begin{array}{l}73,217,147,68,437^{\mathrm{a}} \\
\quad 75,204\end{array}$ & $y=2 \mathrm{E}+06 x-1501$ & 0.9993 & 1.88 & 0.86 & 2.62 & $0.50-700.00$ \\
\hline & 1944 & 13.74 & $\begin{array}{l}73,204,68,147,217 \\
\quad 437^{*}, 75\end{array}$ & $y=1 \mathrm{E}+08 x+59,765$ & 0.9995 & 1.12 & 0.27 & 0.82 & $0.50-700.00$ \\
\hline D-Pinitol & 1861 & 12.90 & $\begin{array}{l}73,147,217,260,133 \\
\quad 191,318\end{array}$ & $y=1 \mathrm{E}+09 x-3 \mathrm{E}+06$ & 0.9994 & 1.37 & 6.78 & 20.54 & $0.25-400.00$ \\
\hline Galactose & 1887 & 13.17 & $\begin{array}{l}73,204,191,147,217 \\
205,129,192\end{array}$ & $y=3 \mathrm{E}+08 x-969,018$ & 0.9997 & 0.27 & 4.40 & 13.33 & $5.00-600.00$ \\
\hline Allo-inositol & 1902 & 13.32 & $73,60,102,43,71$ & $y=8 \mathrm{E}+08 x-289,471$ & 0.9990 & 2.22 & 22.49 & 68.16 & $0.50-20.00$ \\
\hline \multirow[t]{2}{*}{ D-Glucose } & 1992 & 13.52 & $\begin{array}{l}73,204,191,147,205 \\
217,129\end{array}$ & $y=2 E+08 x-425,596$ & 0.9994 & 2.88 & 0.30 & 0.91 & $0.25-500.00$ \\
\hline & 2006 & 14.37 & $\begin{array}{l}73,204,191,147,205 \\
\quad 217,129\end{array}$ & $y=1 \mathrm{E}+08 x-186,687$ & 0.9995 & 1.63 & 0.13 & 0.41 & $0.25-500.00$ \\
\hline D-Mannitol & 1959 & 13.90 & $\begin{array}{l}73,319,205,147,217 \\
103,117,320\end{array}$ & $y=6 \mathrm{E}+08 x+210,769$ & 0.9994 & 1.42 & 44.91 & 136.08 & $0.25-500.00$ \\
\hline D-Sorbitol & 1966 & 13.97 & $\begin{array}{l}73,319,147,205,217 \\
103,320,117\end{array}$ & $y=9 \mathrm{E}+08 x-2 \mathrm{E}+06$ & 0.9991 & 1.58 & 0.11 & 0.33 & $0.50-100.00$ \\
\hline D-Chiro-inositol & 1985 & 14.13 & $\begin{array}{l}73,147,318,217,305 \\
191,265,319\end{array}$ & $\mathrm{y}=2 \mathrm{E}+09 x-465,311$ & 0.9996 & 2.17 & 3.56 & 10.80 & $0.125-50.00$ \\
\hline Ononitol & 1988 & 14.19 & $\begin{array}{c}73,217,147,191,133,260 \\
318,159,305,247,218\end{array}$ & $y=1 \mathrm{E}+08 x-2 \mathrm{E}+06$ & 0.9992 & 0.19 & 25.13 & 76.16 & $12.50-500.00$ \\
\hline Bornesitol & 2035 & 14.65 & $\begin{array}{l}\text { 73, 217, 147, 133, 159 } \\
191,305,318\end{array}$ & $y=1 \mathrm{E}+08 x-230,968$ & 0.9966 & 0.10 & 5.75 & 17.44 & $2.00-250.00$ \\
\hline Scyllo-inositol & 2058 & 14.87 & $\begin{array}{l}73,318,217,147,305,191 \\
204,319,265\end{array}$ & $y=6 \mathrm{E}+08 x-205,566$ & 0.9997 & 0.69 & 4.05 & 12.27 & $0.50-100.00$ \\
\hline Myo-inositol & 2120 & 15.45 & $\begin{array}{l}73,217,147,305,191,318 \\
\quad 204,129,218,265,103,206\end{array}$ & $y=1 \mathrm{E}+09 x-61,935$ & 0.9993 & 1.77 & 9.71 & 29.44 & $0.125-80.00$ \\
\hline Sucrose & 2686 & 20.17 & $\begin{array}{c}73,361,217,147,103,362 \\
129,169,271,437\end{array}$ & $y=4 \mathrm{E}+08 x-359,784$ & 0.9996 & 3.52 & 0.10 & 0.31 & $0.50-700.00$ \\
\hline Lactose & 2730 & 20.47 & $\begin{array}{l}204,73,191,217,205,147 \\
\quad 129,103,206,361\end{array}$ & $y=7 \mathrm{E}+08 x-2 \mathrm{E}+06$ & 0.9987 & 2.36 & 22.21 & 67.34 & $5.00-50.00$ \\
\hline D-Turanose & 2747 & 20.60 & $\begin{array}{l}73,361,147,217,103,129 \\
\quad 204,362\end{array}$ & $y=2 \mathrm{E}+08 x-164,756$ & 0.9997 & 1.12 & 3.56 & 10.68 & $0.50-100$ \\
\hline
\end{tabular}

${ }^{\text {a }}$ fragments used for quantification by extracted ion mod

appeared as different isomers, in the form of two or three peaks. The peaks of fructose (with retention times: 12.67, 12.75 , and $13.73 \mathrm{~min}$ ) are represented by $\alpha$-furanose, $\beta$-furanose, and $\beta$-pyranose, while the two peaks of D-glucose (observed at 13.51 and $14.37 \mathrm{~min}$ ) are equivalent to $\alpha$-pyranose and $\beta$-pyranose, as our results confirm and other researchers mentioned before (Yang 2009). An example presenting a GC tracing of Goldenrod flowers (Solidago virgaurea) extract is presented in Fig. 1. From 17 targets detected in the presented work, 14 of them were present in this extract, while two peaks remained unidentified.

The most frequently appearing cyclitols were myo-inositol, $D$-pinitol, and bornesitol. From these three compounds, we notice that usually, the highest quantities were registered for $D$-pinitol and myo-inositol. Talking about sugar alcohols, sorbitol seems to be present most often than mannitol in plant material. Mushroom is an excellent source of sorbitol, with $21.8 \pm 1.9 \mathrm{mg} / \mathrm{g}$ of dried powder. This amount is more than three times higher than fructose determined in mushrooms. Moreover, in mushroom, all other occurring sugars have very low concentrations compared with sorbitol. The second important source of sorbitol is the parsley, both leaves $(6.8 \pm 0.07 \mathrm{mg} / \mathrm{g}$ of dried plant $)$ and roots $(7.4 \pm 0.5 \mathrm{mg} / \mathrm{g}$ of dried plant). An important source of mannitol is Caraway seeds $(4.4 \pm 0.2 \mathrm{mg} / \mathrm{g}$ of dried powder). 


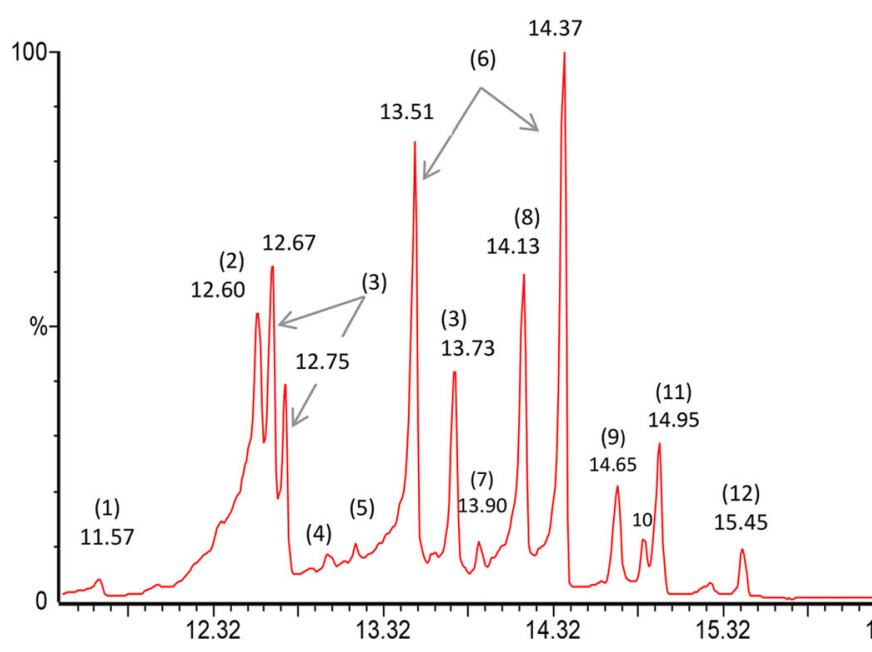

Fig. 1 GC-MS chromatogram presenting the occurrence of target components in Goldenrod flowers, where: 1-Xylose; 2-D-mannose; 3-D-fructose; 4-D-pinitol; 5-galactose; 6-D-glucose; 7-D-

A full list of investigated species is presented in Table 3, where the quantities of all sugars and cyclitols occurring in each sample can be also observed. The results are presented in $\mathrm{mg} / \mathrm{g}$ of dried plant, together with standard deviation calculated for three different replicates.

\section{Distribution of Cyclitols in Plants}

Because our particular interest was to find the most relevant sources of cyclitols, during data processing, a remarkable observation caught our attention. It was generally observed that if plants are rich in cyclitols, they are usually rich in all of them. But, this fact will not facilitate too much the extraction possibility in case that some target compounds are needed to be isolated from all those present in the matrix. The valuable observation was that, there are some plants which are significantly rich in one compound in comparison with others present in the extract. Consequently, those plants that present this specific advantage can be used in industrial extraction. In Fig. 2, bar graphs highlighting 10 of the most relevant sources of each investigated cyclitol are presented. The darker bars represent the sources uninvestigated so far, while the lighter bars present the plants in which the cyclitols were previously found. For example, Mountain Ash fruits (Sorbus aucuparia) are an excellent source of D-chiroinositol, containing $1.44 \pm 0.07 \mathrm{mg} / \mathrm{g}$ of dried plant. The occurrence of all other cyclitols was less than $1 \mathrm{mg} / \mathrm{g}$ of dried plant. In comparison with all investigated plants, Mountain Ash fruits contain about 3.5 times more $D$ chiro-inositol than others. It is worth mentioning that cyclitol content in this plant was not investigated before. Due to this fact, and especially because of the important role of D-chiro-inositol, the fruits of this plant may be the
Scan El+ TIC $1.48 \mathrm{e} 9$

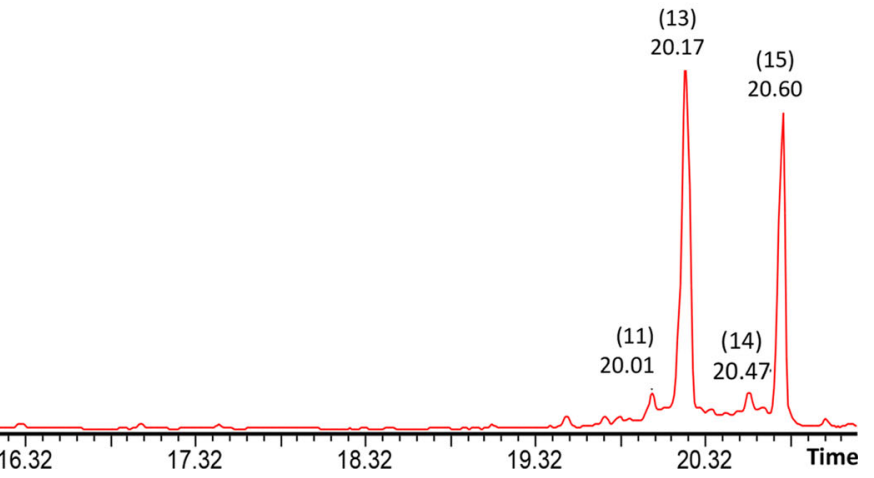
mannitol; 8-Chiro-inositol; 9-Bornesitol; 10-Scyllo-inositol; $11-$ unknown; 12-Myo-inositol; 13-Sucrose; 14-Lactose; 15-Dturanose

perfect candidates for extraction of this cyclitol at pharmaceutically or industry level.

Carob pods (Ceratonia siliqua L.) have proven to contain larger amounts of D-pinitol in comparison with other investigated species (about 25 times more). However, cyclitol content in carob pods was already investigated in other studies.

Regarding myo-inositol, cinnamon, lettuce leaves, and blueberry fruits proved to contain a quantity approximately double compared with other investigated plants. Not one of them was investigated before.

Allo-inositol is quite a rare cyclitol. Its curative properties seem not to be studied so far, maybe exactly for this reason. However, allo-inositol is one of the four possible isomers derived from myo-inositol [20]. Allo-inositol was detected in 14 samples from the 52 investigated. The richest sources of allo-inositol are blueberries, which contain $10.8 \pm 0.2 \mathrm{mg} / \mathrm{g}$ of dried fruit. This fact could make them extremely suited for allo-inositol extraction. Moreover, the amount of other cyclitols present in blueberries is significantly lower than that of allo-inositol. Ononitol (4-O-methyl-myo-inositol), which belongs to the class of methyl myo-inositols, is another rare cyclitol. Ononitol is a cyclohexane-1,2,3,4,5-pentol substituted by a methoxy group at position 6. It was found in 14 samples and the highest amount has been found in blueberries as well $(3.2 \pm 0.5 \mathrm{mg} / \mathrm{g}$ of dried fruit). However, the occurrences of ononitol in other plants like wild garlic, garlic, kale, mint, or dill, even in smaller quantities, make them suitable for ononitol extraction, because they contain reduced quantities of cyclitols compared with the mentioned one.

Bornesitol is one of frequently appearing cyclitol in plants. An alternative name is D-1-O-methyl-myo-inositol; it is the methyl ether of D-myo-inositol. The highest quantity appeared in goldenrod flowers $(2.6 \pm 0.4 \mathrm{mg} / \mathrm{g}$ of 


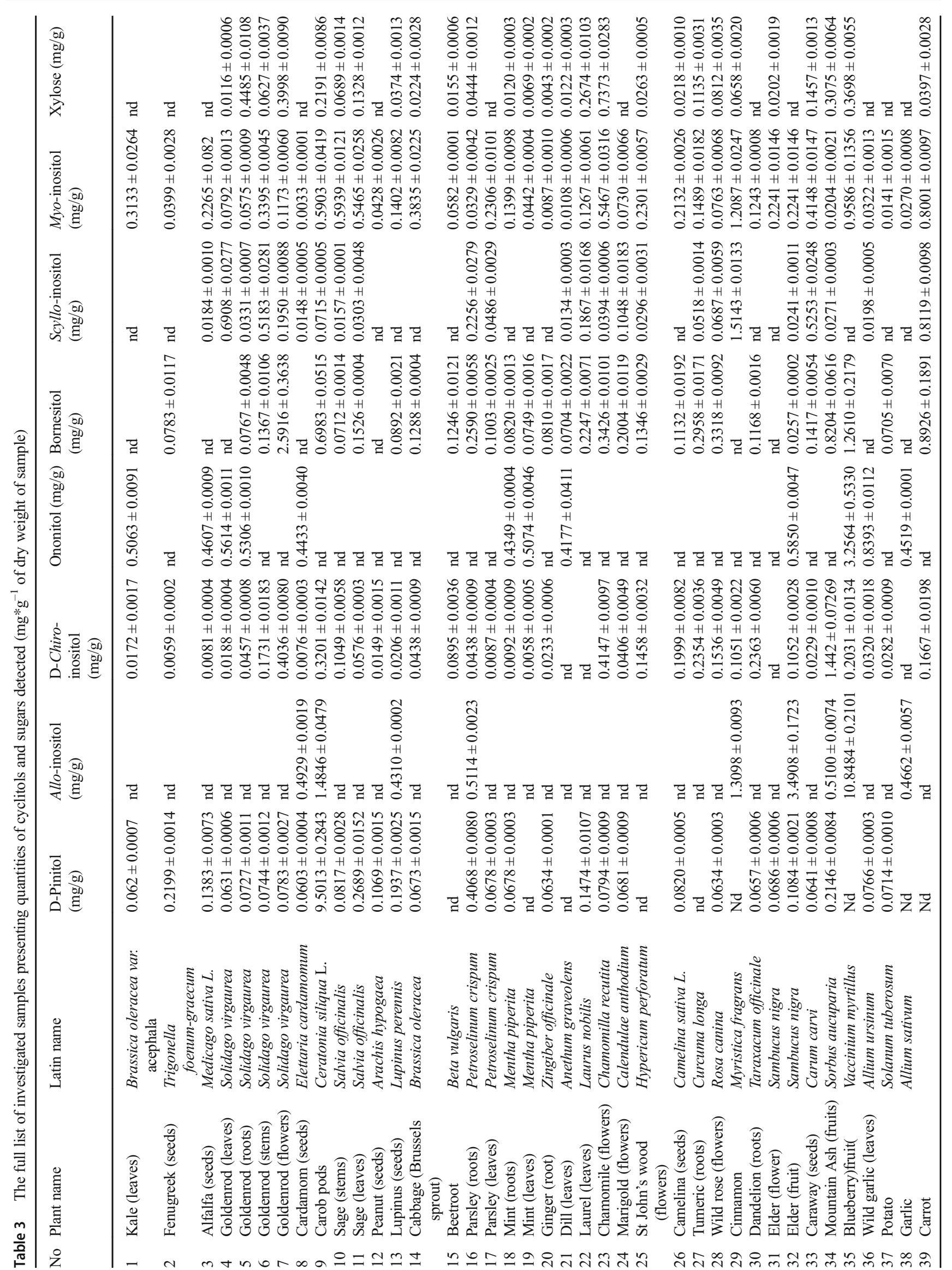




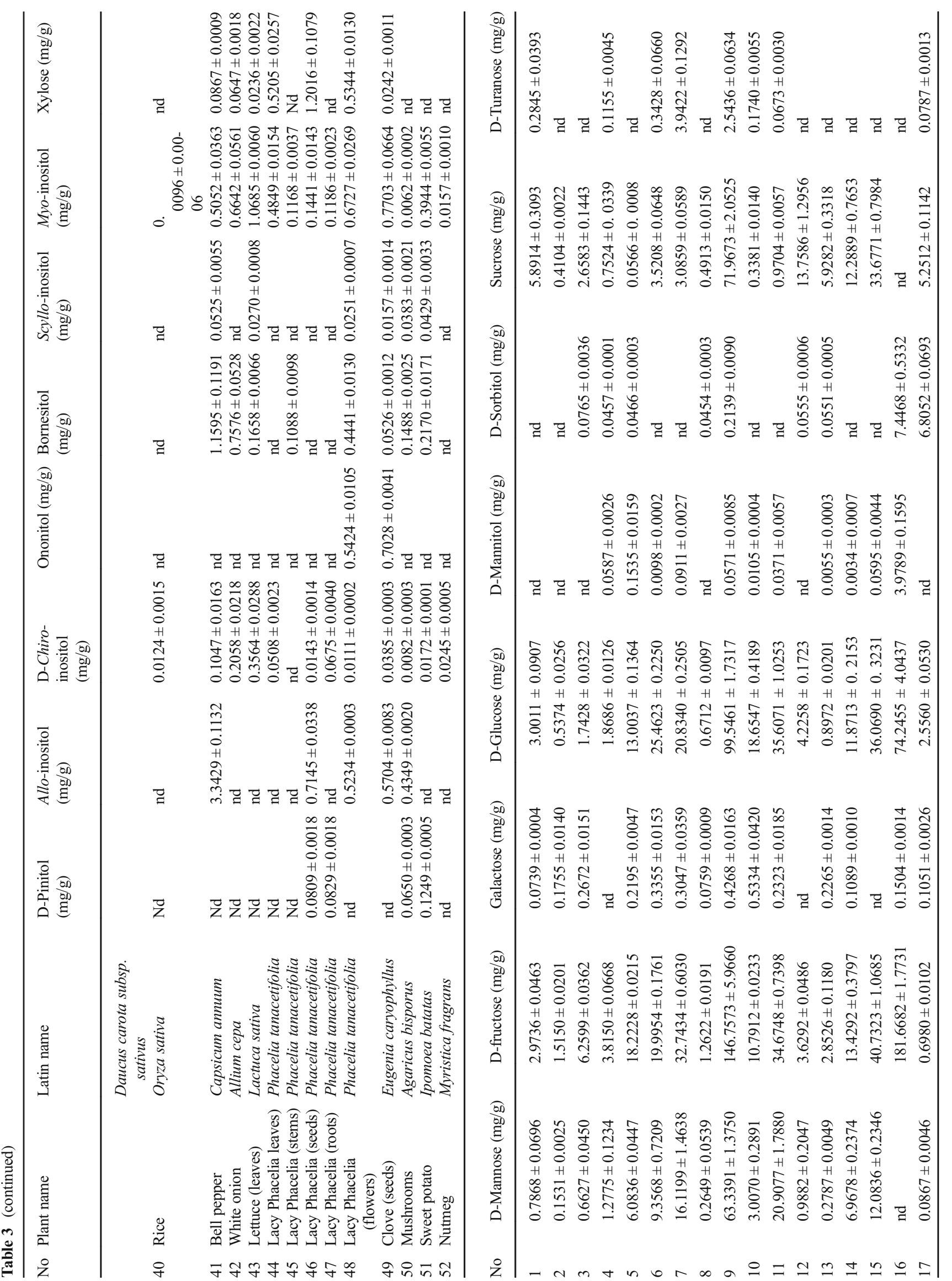




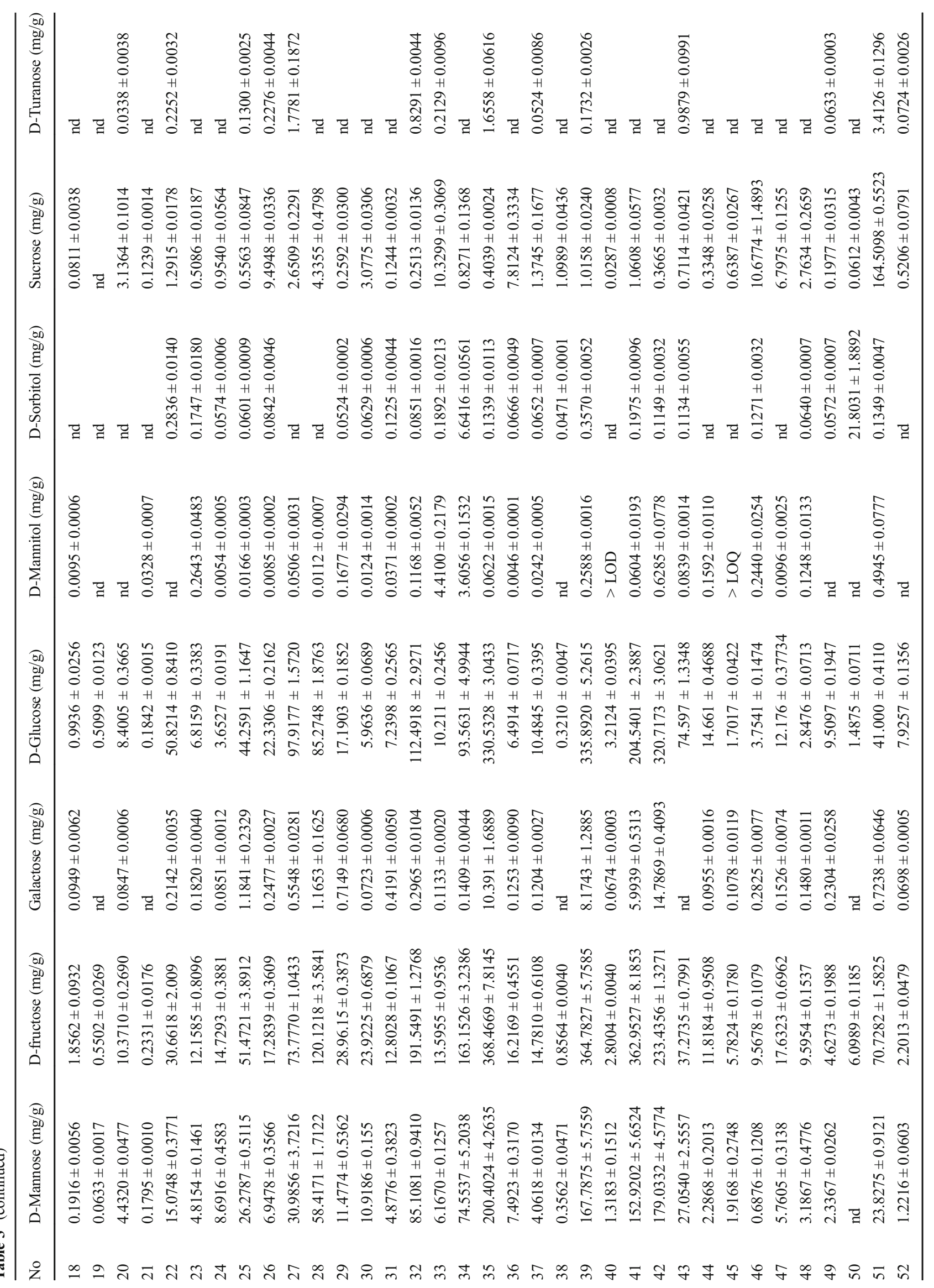




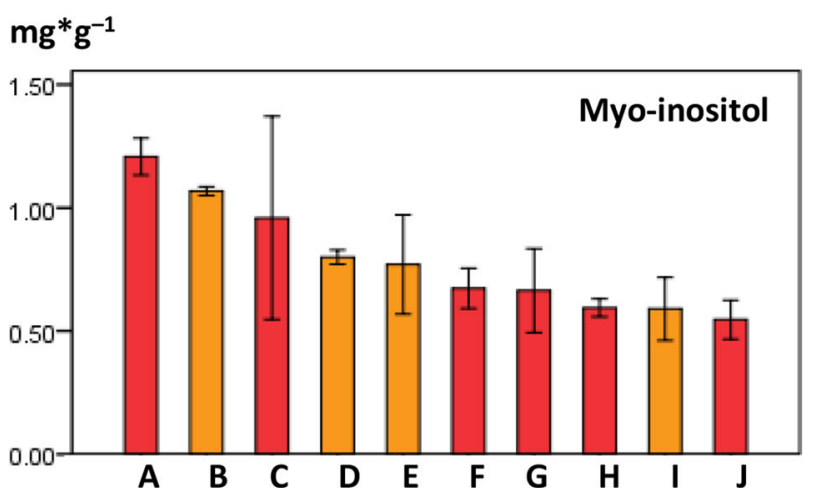

$\mathrm{mg}^{*} \mathrm{~g}^{-1}$
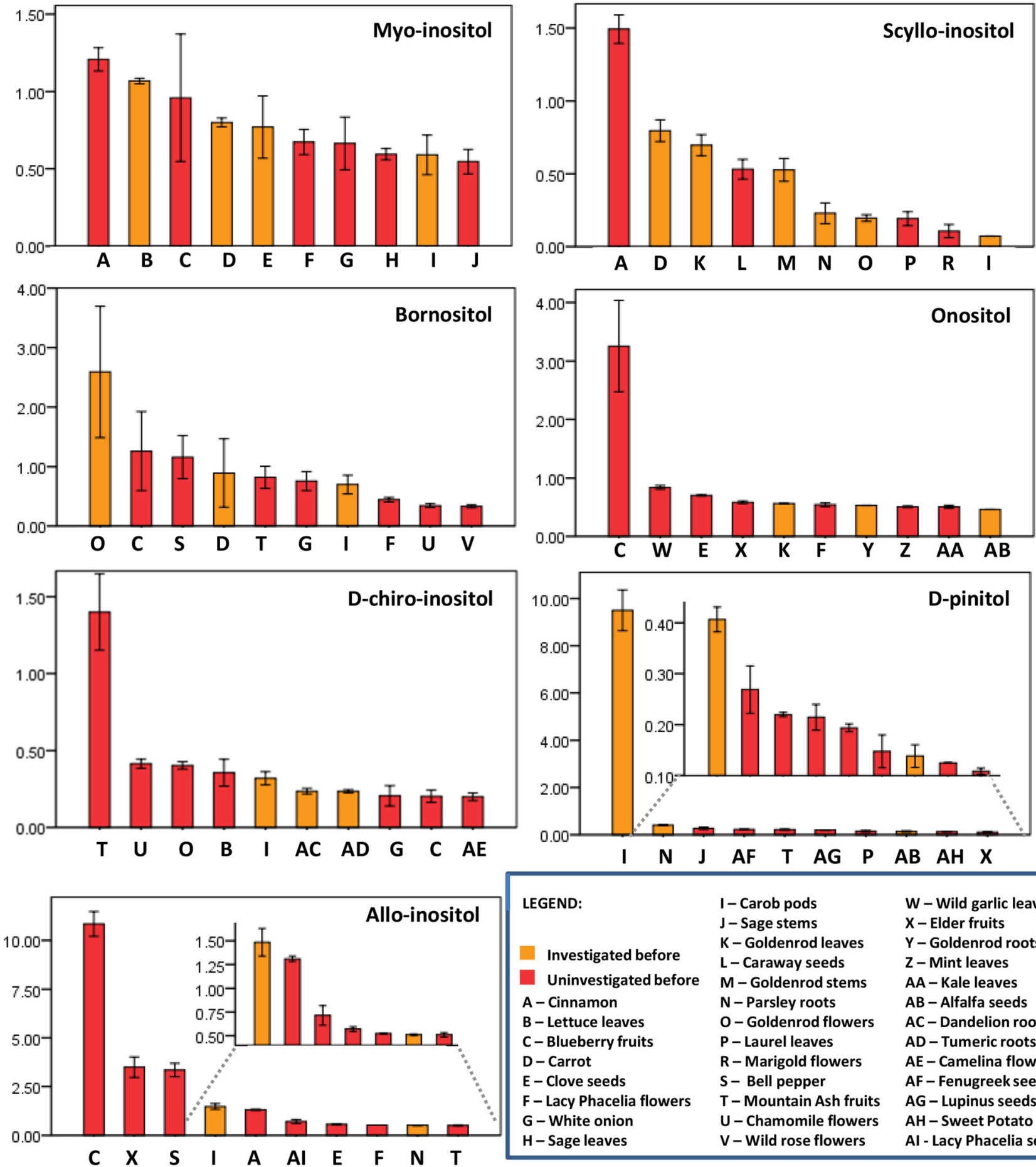

\begin{tabular}{|c|c|c|}
\hline LEGEND: & I-Carob pods & W - Wild garlic leaves \\
\hline & J - Sage stems & $\mathrm{X}$ - Elder fruits \\
\hline & K-Goldenrod leaves & Y - Goldenrod roots \\
\hline & L - Caraway seeds & Z - Mint leaves \\
\hline Uninvestigated before & M - Goldenrod stems & AA - Kale leaves \\
\hline A-Cinnamon & N-Parsley roots & AB - Alfalfa seeds \\
\hline B - Lettuce leaves & O-Goldenrod flowers & AC-Dandelion root \\
\hline C-Blueberry fruits & P - Laurel leaves & AD - Tumeric roots \\
\hline D-Carrot & R-Marigold flowers & AE - Camelina flowers \\
\hline E - Clove seeds & S- Bell pepper & AF - Fenugreek seeds \\
\hline F - Lacy Phacelia flowers & T - Mountain Ash fruits & AG - Lupinus seeds \\
\hline G - White onion & U - Chamomile flowers & AH - Sweet Potato \\
\hline $\mathrm{H}$ - Sage leaves & V-Wild rose flowers & Al - Lacy Phacelia seeds \\
\hline
\end{tabular}

Fig. 2 The richest 10 sources of cyclitols detected in investigated samples

dried plant), where bornesitol was investigated previously, but in a mixture including all aerial parts together. Our detailed analysis of all goldenrod parts confirms that the highest quantity can be found in flowers. Scyllo-inositol was found in 30 of the 52 samples, and the most relevant amount was found in cinnamon $(1.5 \pm 0.01)$, a source from where it was not investigated before.

\section{Distribution of Sugars in Different Morphological Parts of the Plant}

In case of plants for which different morphological parts were investigated in the study, another two important observations came to our attention: firstly, the amount of sugars is significantly different from a certain part of the investigated plant to 
Fig. 3 Sunburst chart representing variation in sugars concentration in different parts of plants, where $1=$ fructose, 2 = glucose, 3 = mannose, 4 = sucrose

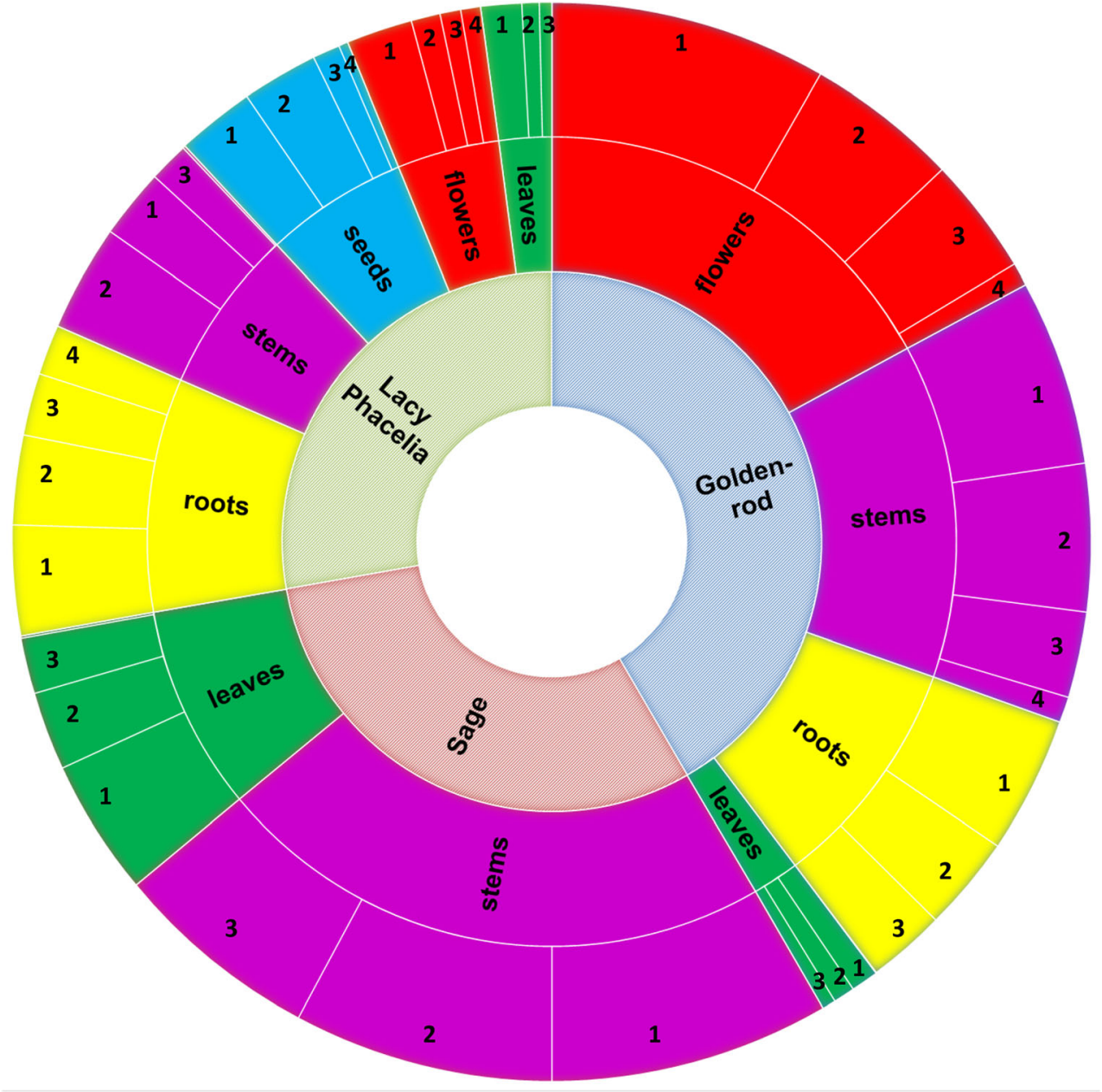

another one, and secondly, the smallest quantities were always detected in leaves. This fact is highlighted in Fig. 3, where a sunburst chart representing variation of sugar concentrations found in different parts of plants was used to support this statement. Three plants with comparable detected quantities of sugars were chosen, but this assumption is believed to be valid for all cases.

The explanation of this phenomenon is that in plant material, sugars are produced in the leaves during photosynthesis. Because they play an important role in plant nutrition, they are

Table 4 Top 10 most important sources of cyclitols investigated

\begin{tabular}{|c|c|c|c|c|c|c|c|c|}
\hline & $\begin{array}{l}\text { D- } \\
\text { Pinitol }^{\mathrm{a}}\end{array}$ & $\begin{array}{l}\text { Allo- } \\
\text { inositol }^{\mathrm{a}}\end{array}$ & $\begin{array}{l}\text { Chiro- } \\
\text { inositol }^{\mathrm{a}}\end{array}$ & Ononitol $^{\mathrm{a}}$ & Bornesitol $^{\mathrm{a}}$ & $\begin{array}{l}\text { Scyllo- } \\
\text { inositol }^{\mathrm{a}}\end{array}$ & $\begin{array}{l}\text { Myo- } \\
\text { inositol }^{\mathrm{a}}\end{array}$ & Total amount $\mathrm{t}^{\mathrm{a}}$ \\
\hline Blueberry fruits & 0 & 10.84 & 0.203 & 3.256 & 1.261 & 0 & 0.958 & 16.518 \\
\hline Carob pods & 9.501 & 1.484 & 0.320 & 0 & 0.698 & 0.071 & 0.590 & 12.664 \\
\hline Bell pepper & 0 & 3.342 & 0.104 & 0 & 1.159 & 0.052 & 0.505 & 5.162 \\
\hline Elder fruits & 0.108 & 3.490 & 0.105 & 0.585 & 0.025 & 0.024 & 0.224 & 4.561 \\
\hline Cinnamon & 0 & 1.309 & 0.105 & 0 & 0 & 1.514 & 1.208 & 4.136 \\
\hline Goldenrod flowers & 0.078 & 0 & 0.403 & 0 & 2.592 & 0.195 & 0.117 & 3.385 \\
\hline Mountain Ash fruits & 0.214 & 0.510 & 1.444 & 0 & 0.820 & 0.027 & 0.020 & 3.035 \\
\hline Carrot & 0 & 0 & 0.166 & 0 & 0.890 & 0.811 & 0.800 & 2.667 \\
\hline Lacy Phacelia flowers & 0 & 0.523 & 0.011 & 0.542 & 0.444 & 0.025 & 0.672 & 2.217 \\
\hline Clove seeds & 0 & 0.570 & 0.038 & 0.702 & 0.052 & 0.015 & 0.770 & 2.147 \\
\hline
\end{tabular}

${ }^{\mathrm{a}}$ The quantities are presented are expressed in $\mathrm{mg}^{*} \mathrm{~g}^{-1}$ of dry weight of sample; each value represent the mean of three replicates 
transported to the whole parts of plant by a vascular tissue called phloem. Within phloem, sugars are transported from high osmotic concentration and high-water-pressure areas, to regions with low osmotic concentration and low water pressure. Thus, the sugars are produced in the leaves, which act like sources, and transported to the roots, which act as sinks. Sometimes, even stems can act as sinks. During flowering period, the phloem transports important part of dissolved sugars to help in the development of flowers and future fruits and seeds (Noiraud et al. 2001).

Dissimilarities highlighted in sugars and cyclitol distribution can be produced as well by other factors, such as climate influence, precipitations, type of soil, cultivation area, etc. All these aspects can strongly influence the occurrence of sugars and cyclitol quantity in plant material (Ratiu et al. 2018).

\section{Top 10 Relevant Plants Suitable for Cyclitol's Extraction}

Cyclitols are the basis, the novelty, and the very justification for the present work. Given the complexity and large amount of data presented previously in the figures and tables, a simplified table showing the top ten sources with the highest concentration of the cyclitols is presented in Table 4. From this ten sources, seven of them, namely, Blueberry fruits, Mountain Ash fruits, Bell pepper, Elder fruits, Cinnamon, Goldenrod flowers, and Lacy Phacelia flowers, were not investigated so far for cyclitol's extraction.

\section{Conclusions}

The study of sugars and cyclitol distribution in plants in terms of recovery from various plants, in order to enrich the range of relevant natural sources used nowadays for their extraction, could lead to high-value economic benefits, besides the medical advantages. It is worth mentioning that cyclitols possess a crucial role as curative agents and most of their natural sources remained unexplored before now. Moreover, sugars alcohols (sorbitol and manitol) are the perfect candidates to be used in food industry instead of classical sugars. Consequently, the results highlighted in the present study can represent valuable information for food, pharmaceutical, medical, or cosmetic industry interested to involve the cyclitols in the manufacture of food supplements, medicines, or cosmetics.

Funding information This work was financed in the framework of the grant entitled: "Cultivated plants and natural products as a source of biologically active substances destined for the production of cosmetic and pharmaceutical products as well as diet supplements" (No. BIOSTRATEG2/298205/9/NCBR/2016) attributed by the National Center for Research and Development (Warsaw, Poland).

\section{Compliance with Ethical Standards}

Conflict of Interest Ileana Andreea Ratiu declares that she has no conflict of interest. Hossam Al-Suod declares that he has no conflict of interest. Magdalena Ligor declares that she has no conflict of interest. Tomasz Ligor declares that he has no conflict of interest. Aneta Krakowska declares that she has no conflict of interest. Ryszard Górecki declares that he has no conflict of interest. Bogusław Buszewski declares that he has no conflict of interest.

Ethical Approval This article does not contain any studies with human participants or animals performed by any of the authors.

Informed Consent Not applicable.

Open Access This article is distributed under the terms of the Creative Commons Attribution 4.0 International License (http:// creativecommons.org/licenses/by/4.0/), which permits unrestricted use, distribution, and reproduction in any medium, provided you give appropriate credit to the original author(s) and the source, provide a link to the Creative Commons license, and indicate if changes were made.

Publisher's Note Springer Nature remains neutral with regard to jurisdictional claims in published maps and institutional affiliations.

\section{References}

Al-Suod H, Ligor M, Ratiu IA, Rafinska K, Górecki R, Buszewski B (2017) A window on cyclitols: characterization and analytics of inositols. Phytochem Lett 20:507-519

Al-Suod H, Ratiu I-A, Ligor M, Ligor T, Buszewski B (2018a) Determination of sugars and cyclitols isolated from various morphological parts of Medicago sativa L. J Sep Sci 41:1118-1128

Al-Suod H, Pomastowski P, Ligor M, Railean-Plugaru V, Buszewski B (2018b) New approach for fast identification of cyclitols by MALDI-TOF mass spectrometry. Phytochem Anal 29(5):528-537

Al-Suod H, Ratiu IA, Górecki R, Buszewski B (2019) Pressurized liquid extraction of cyclitols and sugars: optimization of extraction parameters and selective separation. J Sep Sci. https://doi.org/10.1002/jssc. 201801269

Carlomagno G, Unfer V, Buffo S, D’Ambrosio F (2011) Myo-inositol in the treatment of premenstrual dysphoric disorder. Hum Psychopharmacol Clin Exp 26:526-530

Deis, R.C., Kearsley M.W.P., 2012. Sorbitol and Mannitol, in Sweeteners and Sugar Alternatives in Food Technology, Second Edition, Edited by Dr Kay O'Donnell Weybridge, UK and Dr Malcolm W. Kearsley Reading, UK, A John Wiley \& Sons, Ltd., Publication, pp 331-346

Dewangan P, Verma A, Kesharwani D (2014) Isolation of D-Pinitol: a bioactive carbohydrate from the leaves of Bauhinia variegata L. Int J Pharm Sci Rev Res 24:43-45

Dominguez MA, Jacksén J, Emmer Å, Centurión ME (2016) Capillary electrophoresis method for the simultaneous determination of carbohydrates and proline in honey samples. Microchem J 129:1-4

Egamberdieva D, Mamadalieva N, Khodjimatov O, Tiezzi A (2012) Medicinal plants from Chatkal biosphere reserve used for folk medicine in Uzbekistan. Med Aromat Plant Sci Biotechnol 7:56-64

Feig DI (2010) Sugar-sweetened beverages and hypertension. Futur Cardiol 6:773-776

Filip M, Vlassa M, Coman V, Halmagyi A (2016) Simultaneous determination of glucose, fructose, sucrose and sorbitol in the leaf and fruit peel of different apple cultivars by the HPLC-RI optimized method. Food Chem 199:653-659 
Ghfar AA, Wabaidur SM, Yacine A, Alothman ZA, Khan MR, AlShaalan NH (2015) Simultaneous determination of monosaccharides and oligosaccharides in dates using liquid chromatographyelectrospray ionization mass spectrometry. Food Chem 176:487492

Ghoreishi SM, Shahrestani RG (2009) Innovative strategies for engineering mannitol production. Trends Food Sci Technol 20:263-270

Gomez-Gonzalez S, Ruiz-Jimenez J, Priego-Capote F, De Castro MDL (2010) Qualitative and quantitative sugar profiling in olive fruits, leaves, and stems by gas chromatography-tandem mass spectrometry (GC-MS/MS) after ultrasound-assisted leaching. J Agric Food Chem 58:12292-12299

Grabitske HA, Slavín JL (2008) Perspectives in practice low-digestible carbohydrates in practice. J Am Diet Assoc 108:1677-1681

Gross LS, Li L, Ford ES, Liu S (2004) Increased consumption of refined carbohydrates and the epidemic of type 2 diabetes in the United States: an ecologic assessment. Am J Clin Nutr 79:774-779

Japan Ministry of Health, Labour and Welfare, 2007. Japan's specifications and standards for food additives (8th ed.). Tokyo: Ministry of Health, Labour and Welfare, 1-674. https://www.ffcr.or.jp/en/tenka/ japans-specifications/japans-specifications-and-standards-for-foodadditives-eighth-edition.html, Accessed in 10.04.18

Kim Y, Chang H (2011) Correlation between attention deficit hyperactivity disorder and sugar consumption, quality of diet, and dietary behavior in school children. Nutr Res Pract 5:236-245

Krakowska A, Rafińska K, Walczak J, Buszewski B (2018) Enzymeassisted optimized supercritical fluid extraction to improve Medicago sativa polyphenolics isolation. Ind Crop Prod 124:931940

Ligor M, Ratiu IA, Kiełbasa A, Al-Suod H, Buszewski B (2018) Extraction approaches used for the determination of biologically active compounds (cyclitols, polyphenols and saponins) isolated from plant material. Electrophoresis 39:1860-1874

Márquez-Sillero I, Cárdenas S, Valcárcel M (2013) Comparison of two evaporative universal detectors for the determination of sugars in food samples by liquid chromatography. Microchem J 110:629-635

Mechri B, Tekaya M, Cheheb H, Hammami M (2015) Determination of mannitol sorbitol and myo inositol in olive tree roots and rhizospheric soil by gas chromatography and effect of severe drought conditions on their profiles. J Chromatogr Sci 53:16311638

Millar L, Rowland B, Nichols M, Swinburn B, Bennett C, Skouteris H, Allendes S (2014) Relationship between raised BMI and sugar sweetened beverage and high fat food consumption among children. Obesity. 22:E96-E103

Monastra G, Unfer V, Harrath AH, Bizzarri M (2017) Combining treatment with myo-inositol and D-chiro-inositol (40:1) is effective in restoring ovary function and metabolic balance in PCOS patients. Gynecol Endocrinol 33:1-9

Muir JG, Rose R, Rosella O, Liels K, Barrett JS, Shepherd SJ, Gibson PR (2009) Measurement of short-chain carbohydrates in common Australian vegetables and fruits by high-performance liquid chromatography (HPLC). J Agric Food Chem 57:554-565

Murphy SP, Johnson R (2003) The scientific basis of recent US guidance on sugars intake. Am J Clin Nutr 78:827S-833S
Noiraud N, Maurousset L, Lemoine R (2001) Identification of a mannitol transporter, AgMaT1, in celery phloem. Plant Cell 13:695-705

Peres MA, Sheiham A, Liu P, Demarco FF, Silva AE, Assunção MC, Menezes AM, Barros FC, Peres KG (2016) Sugar consumption and changes in dental caries from childhood to adolescence. J Dent Res 95:388-394

Pico J, Martínez MM, Martín MT, Gómez M (2015) Quantification of sugars in wheat flours with an HPAEC-PAD method. Food Chem 173:674-681

Ratiu IA, Al-Suod H, Ligor M, Ligor T, Railean-Plugaru V, Buszewski B (2018) Complex investigation of extraction techniques applied for cyclitols and sugars isolation from different species of Solidago genus. Electrophoresis 39:1966-1974

Regulation 1333/2008 of the European Parliament and of the Council of 16 December 2008 on food additives. https://eur-lex.europa.eu/ legal-content/en/TXT/?uri=CELEX\%3A32008R1333. Accessed in 10.04.18

Rengarajan T, Nandakumar N, Rajendran P, Ganesh MK, Balasubramanian MP, Nishigaki I (2015) D-pinitol mitigates tumor growth by modulating interleukins and hormones and induces apoptosis in rat breast carcinogenesis through inhibition of NF-kb. J Physiol Biochem 71:191-204

Ruiz-Aceituno L, Rodriguez-Sanchez S, Sanz J, Sanz ML, Ramos L (2014) Optimization of pressurized liquid extraction of inositols from pine nuts (Pinus pinea L). Food Chem 153:450-456

Ruskone-Fourmestraux A, Attar A, Chassard D, Coffin B, Bornet F, Bouhnik Y (2003) A digestive tolerance study of maltitol after occasional and regular consumption in healthy humans. Eur J Clin Nutr 57:26-30

Shanmugavelan P, Kim SY, Kim JB, Kim HW, Cho SM, Kim SN, Kim SY, Cho YS, Kim HR (2013) Evaluation of sugar content and composition in commonly consumed Korean vegetables, fruits, cereals, seed plants, and leaves by HPLC-ELSD. Carbohydr Res 380:112117

Singh RK, Pandey BL, Tripathi M, Pandey VB (2001) Antiinflammatory effect of (+)-pinitol. Fitoterapia. 72:168-170

Sivakumar S, Subramanian SP (2009) Pancreatic tissue protective nature of D-Pinitol studied in streptozotocin-mediated oxidative stress in experimental diabetic rats. Eur J Pharmacol 622:65-70

United States Food and Drug Administration: 21CFR, 2018. <http:/ www.access- data.fda. gov/scripts/cdrh/cfdocs/cfcfr $>$ Accessed 10. 04.18

Yang B (2009) Sugars, acids, ethyl $\beta$-d-glucopyranose and a methyl inositol in sea buckthorn (Hippophaë rhamnoides) berries. Food Chem 112:89-97

Zheng K, Zhao Z, Lin N, Wu Y, Xu Y, Zhang W (2017) Protective effect of pinitol against inflammatory mediators of rheumatoid arthritis via inhibition of protein tyrosine phosphatase non-receptor type 22 (PTPN22). Med Sci Monit 21:1923-1932 